Emmen, M.J., Meijer, S.A., Verhaak, P.F.M. Positie van de eerstelijnspsycholoog in de geestelijke gezondheidszorg. TSG: Tijdschrift voor Gezondheidswetenschappen: 2008, 86(3), 142-149

\begin{tabular}{|l|l|}
\hline Postprint Version & 1.0 \\
\hline Journal website & http://vb23.bsl.nl/frontend/index.asp?custom_product_id=1388-7491 \\
\hline Pubmed link & \\
\hline DOI &
\end{tabular}

This is a NIVEL certified Post Print, more info at http://www.nivel.eu

\title{
Positie van de eerstelijnspsycholoog in de geestelijke gezondheidszorg
}

\author{
M.J. EMMEN*,S.A. MEIJER** ,P.F.M. VERHAAK*
}

*Nederlands instituut voor onderzoek van de gezondheidszorg (NIVEL)

** Rijksinstituut voor Volksgezondheid en Milieu (RIVM), centrum VTV, Bilthoven

Mevr. Dr. M.J. Emmen, NIVEL, Postbus 1568, 3500 BN Utrecht, tel. 030-2729829, e-mail:

m.emmen@nivel.nl

Eerstelijnspsychologen bieden binnen de eerstelijn kortdurende hulp bij psychische en psychosociale problemen. Er wordt nagegaan in hoeverre de maatregelen ter versterking van de eerstelijns GGZ gedurende de afgelopen 10 jaar geleid hebben tot veranderingen in het aantal eerstelijnspsychologen en de zorg die zij verlenen. Gedurende de afgelopen jaren is de capaciteit aan eerstelijnspsychologen toegenomen. In de hulpverlening door de eerstelijnspsycholoog hebben zich weinig veranderingen voorgedaan. De gemiddelde duur van de behandeling is afgenomen. Ook in de verwijsstromen van en naar de eerstelijnspsycholoog is niet veel veranderd. De meerderheid van de cliënten bij de eerstelijnspsycholoog is doorverwezen door de huisarts en de eerstelijnspsycholoog verwijst een derde deel van de cliënten door naar de tweedelijns geestelijke en somatische gezondheidszorg. Geconcludeerd wordt dat de sterkere positie van de beroepsgroep vooral blijkt uit de toename van het aantal eerstelijnspsychologen. Mogelijke effecten ten gevolge van de opname van de kortdurende eerstelijnspsychologische zorg in het basispakket van de ziektekostenverzekering worden besproken.

\section{KERNPUNTEN}

- Het aantal eerstelijnspsychologen is de afgelopen tien jaar sterk toegenomen.

- De cliënten van eerstelijnspsychologen zijn relatief vaak jong volwassen en zelden ouder dan 65 jaar.

- Eerstelijnspsychologen behandelen vooral interpersoonlijke problemen, aanpassings- en verwerkingsproblemen, depressie en angststoornissen. Hierin is de afgelopen tien jaar weinig veranderd.

- De huisarts is de afgelopen tien jaar iets minder belangrijk geworden als toegang tot de eerstelijnspsycholoog.

INLEIDING

Sinds 1 januari 2008 valt de kortdurende eerstelijnspsychologische zorg onder het basispakket van de ziektekostenverzekering. Deze zorg kan worden aangeboden door diverse hulpverleners, waaronder de eerstelijnspsychologen. Eerstelijnspsychologen zijn 
Emmen, M.J., Meijer, S.A., Verhaak, P.F.M. Positie van de eerstelijnspsycholoog in de geestelijke gezondheidszorg. TSG: Tijdschrift voor Gezondheidswetenschappen: 2008, 86(3), 142-149

psychologen die generalistische kortdurende zorg verlenen, samenwerken met andere eerstelijnsdisciplines en in het register eerstelijnspsychologen van het Nederlands Instituut van Psychologen zijn opgenomen. Over deze relatief jonge beroepsgroep is tot op heden nog niet veel geschreven. In dit artikel wordt beschreven hoe de eerstelijnspsychologen zich de afgelopen jaren een positie in de eerste lijn hebben verworven.

Eerstelijnspsychologen bieden binnen de eerstelijn kortdurende hulp bij psychische en psychosociale problemen. In vergelijking met psychotherapeuten en psychiaters zien eerstelijnspsychologen patiënten met lichtere psychische problemen. ${ }^{1}$ De diverse kenmerken van de hulp door een eerstelijnspsycholoog worden beschreven in de richtlijn intake en indicatiestelling voor eerstelijnspsychologen. ${ }^{2}$ De hulp door de eerstelijnspsycholoog is laagdrempelig: er is geen selectie op grond van cliëntkenmerken. De hulp is van korte duur (maximaal twaalf contacten) en direct toegankelijk (een verwijsbrief is gewenst maar niet noodzakelijk). Eerstelijnspsychologen verrichten doelgerichte diagnostiek die direct bij de klacht aansluit. Ze stellen bijvoorbeeld met behulp van vragenlijsten vast hoe mensen met bepaalde problemen omgaan en hoe de kwaliteit van een eventuele partnerrelatie is. De werkwijze van eerstelijnspsychologen is generalistisch, wat wil zeggen dat zij gebruik maken van een breed hulpaanbod en verschillende methodes voor diverse problemen. De behandeling is gericht op het opheffen van de psychische klachten of het voor de cliënt beter beheersbaar maken van problemen. Zij werken samen met de huisarts en andere eerstelijndisciplines en verwijzen gericht door naar hulpverleners in de tweedelijn wanneer kortdurende hulp onvoldoende is.

Gedurende de afgelopen tien jaar zijn de eerstelijnspsychologen een steeds duidelijkere positie in gaan nemen binnen de gezondheidszorg. Sinds 1998 worden zij door beleidsmakers, samen met de huisarts en het algemeen maatschappelijk werk (AMW) gezien als de kerndisciplines van de eerstelijns GGZ. ${ }^{3}$ Met het AMW ondersteunen zij de huisarts als poortwachter bij de toenemende stroom aan psychische problemen. Wanneer de eerstelijns GGZ het merendeel van de hulpvragen op psychisch gebied opvangt, zou de tweedelijns GGZ, waar een steeds groter beroep op wordt gedaan, ontlast kunnen worden.

De overheid heeft de laatste tien jaar diverse maatregelen getroffen ter versterking van de eerstelijns GGZ. Voor de eerstelijnspsychologen hield dit onder andere in dat er verschillende projecten opgezet werden voor een verbeterde samenwerking met huisartsen en het AMW, voor deskundigheidsbevordering en kwaliteitsverbetering. Kwaliteitsverbetering staat nu nog steeds centraal bij de beroepsvereniging van eerstelijnspsychologen (de Landelijke Vereniging van Eerstelijnspsychologen ofwel LVE). Er zijn richtlijnen opgesteld voor de intake en indicatiestellingen ${ }^{2}$ en werk en psychische klachten, ${ }^{4}$ er is een verplichte herregistratieregeling en de certificering van het praktijkmanagement van een eerstelijnspsychologenpraktijk ${ }^{5}$ wordt gestimuleerd. Verder is er een wachttijdenbeleid (2005) en klachtenregeling (2005) in werking getreden. Bovendien moeten gekwalificeerde eerstelijnspsychologen sinds 2001 in het bezit zijn van de registratie als gezondheidszorgpsycholoog BIG. ${ }^{6}$

Een andere belangrijke maatregel ter bevordering van de toegankelijkheid van de eerstelijns GGZ zou de algemene vergoeding van eerstelijnspsychologische zorg zijn. Sinds in 2002 in de tweede kamer de motie-Buijs werd aangenomen (27855, nr.12), bestaat dit voornemen al. Onderzoek naar verruiming van de financiële toegankelijkheid van eerstelijnspsychologen in twee proefregio's heeft aangetoond dat er, indien de zorg (gedeeltelijk) vergoed wordt, meer cliënten naar de eerstelijnspsycholoog doorverwezen worden en dat ook het aantal lager opgeleide cliënten toeneemt. ${ }^{7}$ Uiteindelijk heeft dit ertoe geleid dat per 1 januari 2008 de eerstelijnspsychologische zorg in de basisverzekering is opgenomen. Vanuit de basisverzekering worden maximaal acht sessies eerstelijnspsychologische zorg vergoed, waarbij cliënten een eigen bijdrage van tien euro per zitting leveren.

Gezien het voorafgaande kan gezegd worden dat er vanuit de overheid en de beroepsvereniging van de eerstelijnspsychologen gedurende de afgelopen jaren diverse maatregelen zijn getroffen en voorzieningen zijn gecreëerd om de positie van de 
Emmen, M.J., Meijer, S.A., Verhaak, P.F.M. Positie van de eerstelijnspsycholoog in de geestelijke gezondheidszorg. TSG: Tijdschrift voor Gezondheidswetenschappen: 2008, 86(3), 142-149

eerstelijnspsychologen binnen de eerstelijns GGZ te versterken. De vraag is of dit ook terug te zien is in het aantal eerstelijnspsychologen en de zorg die zij verlenen. Om dit te onderzoeken zijn de volgende onderzoeksvragen geformuleerd:

- Zijn er in de afgelopen tien jaar meer eerstelijnspsychologen bijgekomen?

- Is er over de afgelopen tien jaar verandering opgetreden in het soort cliënten dat zich bij de eerstelijnspsychologen aanmeldde?

- Is de hulpverlening aan de cliënten gedurende de afgelopen tien jaar veranderd?

- Zijn de verwijsstromen naar de eerstelijnspsycholoog, en diens doorverwijzingen de afgelopen tien jaar gewijzigd?

Een toenemend aantal verwijzingen zou namelijk passen bij de centrale positie van de huisarts als poortwachter ondersteund door het AMW en de eerstelijnspsychologen.

\section{METHODE}

\section{Bronnen van gegevens}

De informatie over de eerstelijnspsychologen is afkomstig uit verschillende bronnen:

\section{Register eerstelijnspsychologen van het Nederlands Instituut van Psychologen}

Het Nederlands Instituut van Psychologen (NIP) is de landelijke beroepsvereniging van psychologen. In het register eerstelijnspsychologen van het NIP zijn alle eerstelijnspsychologen die gekwalificeerd of in opleiding zijn opgenomen. Dit register is geraadpleegd voor het vaststellen van de capaciteit aan eerstelijnspsychologen over de jaren 1998, 2002, 2003, 2004, 2005 en 2006.

\section{Enquêtes onder eerstelijnspsychologen}

In 1998 heeft het Trimbosinstituut in opdracht van het ministerie van VWS en in samenwerking met de Landelijke Vereniging van Eerstelijns Psychologen (LVE) een landelijke enquête uitgevoerd onder psychologen die werkzaam waren in de eerstelijn. ${ }^{1}$ Onder de psychologen naar wie de enquête is verstuurd bevonden zich 751 eerstelijnspsychologen die gekwalificeerd of in opleiding waren. Van hen heeft $49 \%$ de enquête ingevuld. Zij kregen vragen over de hulpverlening en over vijf opeenvolgende cliënten die zij in behandeling hadden. In totaal zijn de gegevens over 2795 cliënten verzameld.

In 2002 heeft het NIVEL een landelijke enquête onder eerstelijnspsychologen gehouden in het kader van een evaluatie studie naar de versterking van de eerstelijns GGZ. ${ }^{8}$ De vragen in de enquête waren vergelijkbaar met die van de enquête van 1998. De vragenlijst is verstuurd naar 896 eerstelijnspsychologen die gekwalificeerd of in opleiding waren en lid van de LVE waren: 418 eerstelijnspsychologen (47\%) hebben de vragenlijst ingevuld en eveneens informatie gegeven over 1124 cliënten.

Er is gebruik gemaakt van de beide enquêtes voor gegevens over hulpverlening en verwijsstromen in de jaren 1998 en 2002

\section{Landelijk Informatienetwerk Eerstelijns Psychologen}

Het Landelijk Informatie Netwerk Eerstelijnspsychologen (LINEP) is een informatienetwerk dat bestaat uit ongeveer 50 eerstelijnspsychologen die zich aangemeld hebben als peilstation. De peilstations zijn verspreid over Nederland en representatief voor de diverse zorgregio's en de mate van verstedelijking. Per kwartaal leveren zij gegevens over de contacten met cliënten aan die op uniforme wijze geregistreerd zijn. Zo worden onder andere personalia, de aanmeldingsklacht en het type en de duur van de behandeling geregistreerd. Hiervoor worden codes gebruikt die in een codeboek staan. Dit codeboek is opgesteld door de LVE. Op dit moment moet iedere eerstelijnspsycholoog iedere afgesloten behandeling in dit LVE codeboek bijhouden voor herregistratie. 
Emmen, M.J., Meijer, S.A., Verhaak, P.F.M. Positie van de eerstelijnspsycholoog in de geestelijke gezondheidszorg. TSG: Tijdschrift voor Gezondheidswetenschappen: 2008, 86(3), 142-149

De registratiegegevens van LINEP komen sterk overeen met de registratiegegevens van de eerstelijnspsychologen op landelijk niveau. Elk jaar verschijnt er een jaarbericht waarin de geanonimiseerde codeboekgegevens van de eerstelijnspsychologen landelijk samengevoegd zijn. De LINEP gegevens komen goed overeen met de gegevens uit het LVE jaarbericht 2004 (gegevens van 416 eerstelijnspsychologen en 25.925 cliënten) en het LVE jaarbericht 2005 (gegevens van 726 eerstelijnspsychologen en 52.000 cliënten) en LVE jaarbericht 2006 (gegevens van 696 psychologen en 52.430 cliënten) .

LINEP beschikt over gegevens sinds 2004. Over het jaar 2004 hebben 32 peilstations registratiegegevens over 3579 cliënten gegeven. Over het jaar 2005 betrof het de registratiegegevens van 42 peilstations over 4285 cliënten. Over het jaar 2006 hebben 48 peilstations registratiegegevens over 4948 cliënten gegeven. In dit artikel zijn de gegevens van LINEP over de jaren 2004, 2005 en 2006 gebruikt voor gegevens over hulpverlening en verwijsstromen.

\section{Data-analyse}

De resultaten zijn geanalyseerd met het statistiekprogramma SPSS. Er is voornamelijk beschrijvende statistiek toegepast: frequentieverdelingen, gemiddelden en percentages. Indien mogelijk is er getoetst of er verschillen over de jaren zijn. Daar waar verschillen in gemiddelde scores zijn getoetst, is gebruik gemaakt van een ANOVA. Om te zien waar de verschillen zitten, zijn er post hoc tests uitgevoerd (Bonferroni). Daar waar verschillen in verdeling zijn getoetst, is gebruik gemaakt van een chikwadraat toets (bij crosstabs). Een pwaarde kleiner dan 0.05 is significant.

\section{RESULTATEN}

\section{Capaciteit eerstelijnspsychologen}

Het aantal eerstelijnspsychologen is snel gegroeid. In figuur 1. wordt de totale capaciteit van eerstelijnspsychologen (inclusief eerstelijnspsychologen in opleiding) per 100.000 inwoners voor de afgelopen negen jaar weergegeven. Het aantal eerstelijnspsychologen is in de periode van 1998 tot en met 2006 toegenomen van vijf tot acht eerstelijnspsychologen per 100.00 inwoners. Het betreft hier niet het aantal fte, maar het aantal personen. Geschat wordt dat één eerstelijnspsycholoog gemiddeld 0,5-0,8 fte vervult.

\section{[FIGURE 1]}

\section{Cliënten}

De kenmerken van cliënten van de eerstelijnspsycholoog gedurende de afgelopen tien jaar worden in tabel 1 gepresenteerd.

Tweederde van de cliënten is vrouw en dat percentage blijft ongeveer gelijk over de jaren. Vergeleken met de algemene bevolking bevinden zich relatief veel vrouwen in het cliëntenbestand van de eerstelijnspsycholoog.

Wat betreft de opleiding van cliënten van eerstelijnspsychologen is er sprake van een ontwikkeling: vanaf het eerste meetmoment in 1998 is er een afname in de groep laagopgeleiden (geen opleiding/lagere beroepsopleiding/MAVO) en een toename in de groep met een middelbare opleiding (HAVO/MBO/VWO). In het laatste meetjaar, 2006, zijn de laagst opgeleide groepen ondervertegenwoordigd ten opzichte van de Nederlandse bevolking en de hoger opgeleide groepen oververtegenwoordigd.

Het percentage cliënten van niet-Nederlandse afkomst neemt tussen 1998 en 2002 toe van $4 \%$ tot ongeveer $7 \%$ en blijft de jaren daarna ongeveer gelijk. Gelet op deze percentages ziet de eerstelijnspsycholoog weinig cliënten van niet-Nederlandse afkomst in verhouding tot het percentage allochtonen in de algemene bevolking.

De gemiddelde leeftijd van de cliënten van de eerstelijnspsycholoog is ongeveer 38 jaar en blijft over de jaren gelijk. Letten we op verschillende leeftijdscategorieën dan neemt het 
Emmen, M.J., Meijer, S.A., Verhaak, P.F.M. Positie van de eerstelijnspsycholoog in de geestelijke gezondheidszorg. TSG: Tijdschrift voor Gezondheidswetenschappen: 2008, 86(3), 142-149

aandeel van de jongvolwassenen (25-44 jaar) af en het aandeel van de oudere volwassene (45-64 jaar) toe. Vergeleken met de Nederlandse bevolking blijft de categorie jongvolwassenen sterk oververtegenwoordigd en zijn met name 65-plussers ondervertegenwoordigd.

\section{[TABLE 1]}

\section{In behandeling genomen problematiek}

Tabel 2 geeft een overzicht van de probleemgebieden die voorkwamen bij de cliënten van eerstelijnspsychologen tussen 1998 en 2006. De registratie binnen LINEP, waaraan de gegevens van 2004 - 2005 - 2006 ontleend zijn, hanteert in sommige gevallen andere categorieën waardoor de gegevens 1998-2002 niet volledig vergelijkbaar zijn. Gezien deze verschillen worden de gegevens over 1998 en 2002 wel gepresenteerd maar niet statistisch getoetst ten opzichte van 2004, 2005 en 2006.

\section{[TABLE 2]}

De onderscheiden probleemgebieden in de enquêtes en registratie van eerstelijnspsychologen zijn in vier hoofdgroepen ondergebracht: psychische problemen, relationele problemen, problemen die verband houden met gezondheid en een restcategorie.

De grootste hoofdgroep, de laatste jaren ongeveer $60 \%$, wordt gevormd door de psychische problemen, gevolgd door de relationele problemen die een kwart van alle probleemgebieden uitmaken. Problemen die met de gezondheid verband houden vormen ongeveer $10 \%$ van alle geregistreerde problemen en minder dan $10 \%$ valt in de categorie "overigen".

De meest voorkomende probleemgebieden zijn interpersoonlijke problemen, verwerkingsproblemen, depressies en angststoornissen. In periode $2004-2006$ is een significante afname te constateren in aangemelde "werk en studieproblemen".

\section{Hulpverlening door eerstelijnspsychologen}

De enquêtes $(1998,2002)$ en LINEP registratie (2004 - 2006) verschaften ook informatie over de hulpverlening die de eerstelijnspsychologen bieden. Over alle jaren krijgt tweederde van de cliënten hulpverlening in de vorm van een behandeling. Andere vormen van hulpverlening zijn advies/consultatie en oriënterende gesprekken. Deze maken ieder ongeveer een tiende deel uit van de hulpverlening. Het percentage crisisinterventies en ondersteuning is vanaf 1998 afgenomen van $17 \%$ naar $10 \%$.

De gemiddelde wachttijd, de tijd tussen de aanmelding en de eerste sessie, voor een cliënt fluctueert in de periode van 1998 tot en met 2006 tussen de tien en negentien dagen. Hoewel er geen duidelijk patroon in afname en toename te zien is, lijkt de wachttijd eerder toe dan af te nemen.

In de afgelopen jaren is het gemiddelde aantal sessies ofwel zittingen per cliënt significant afgenomen. In 1998 had een cliënt gemiddeld nog vijftien sessies over een gemiddelde duur van 5,7 maanden. In 2006 is dit gereduceerd tot zeven sessies over een gemiddelde duur van 4,0 maanden. Bijna driekwart van de cliënten heeft niet meer dan acht sessies.

\section{Verwijsstromen}

\section{Verwijzingen naar eerstelijnspsychologen}

Tabel 3 toont dat gedurende de afgelopen jaren het percentage cliënten dat via de huisarts naar de eerstelijnspsycholoog verwezen wordt, geleidelijk is afgenomen en het percentage cliënten dat op eigen initiatief komt, geleidelijk is toegenomen $(p<0,05)$. Cliënten worden verder naar een eerstelijnspsycholoog verwezen door andere hulpverleners zoals de bedrijfsarts of het bedrijfsmaatschappelijk werk, het AMW, een andere eerstelijnspsycholoog of een schoolarts. 
Emmen, M.J., Meijer, S.A., Verhaak, P.F.M. Positie van de eerstelijnspsycholoog in de geestelijke gezondheidszorg. TSG: Tijdschrift voor Gezondheidswetenschappen: 2008, 86(3), 142-149

\section{[TABEL 3]}

\section{Verwijzingen vanuit eerstelijnspsychologen}

In tabel 4 wordt getoond naar welke hulpverleners cliënten van de eerstelijnspsycholoog over de tijd zijn doorverwezen. Na 1998 zijn eerstelijnspsychologen een significant groter deel van hun cliënten gaan doorverwijzen. De toename zit met name in de cliënten die naar de tweedelijns GGZ worden verwezen.

\section{[TABEL 4]}

\section{DISCUSSIE}

\section{Zijn er in de afgelopen tien jaar meer eerstelijnspsychologen bijgekomen?}

Gedurende de afgelopen tien jaar is de capaciteit aan eerstelijnspsychologen toegenomen van vijf tot acht per 100.000 inwoners. Deze toename blijft nog achter bij het streven van de Landelijke Vereniging van Eerstelijnspsychologen naar veertien eerstelijnspsychologen per 100.000 inwoners, met een gemiddelde inzet van 65 tot $70 \%$ van full-time. Capaciteitsvergroting is belangrijk vanwege de verwachte toename in vraag naar eerstelijnspsychologische zorg, als gevolg van de opname van eerstelijnspsychologische zorg in de basisverzekering. Onderzoek naar verruiming van de financiële toegankelijkheid van eerstelijnspsychologen heeft aangetoond dat een huisarts meer cliënten naar de eerstelijnspsycholoog gaat verwijzen in plaats van naar de gespecialiseerde GGZ, wanneer deze zorg door de verzekering gedekt is. ${ }^{7}$ Deze verwachting wordt ondersteund door het gegeven dat er veel mensen met psychische en sociale problemen zijn met een latente hulpbehoefte. ${ }^{10} \mathrm{Nu}$ hulp voor hun psychische en sociale problemen onder de basisverzekering valt, gaan deze mensen daar mogelijk ook een beroep op doen.

De verwachte toenemende vraag naar eerstelijnspsychologische hulp hoeft echter niet uitsluitend beantwoord te worden door de eerstelijnspsychologen, maar kan ook verleend worden door andere zelfstandig gevestigde GZ-psychologen. Naar schatting is er een groep van 350-750 GZ-psychologen die vrijgevestigde werkzaamheden verrichten die zich laten kenschetsen als eerstelijnspsychologische zorg. ${ }^{11}$

\section{Is er verandering opgetreden in het soort cliënten dat zich aanmeldde?}

De cliënten van de eerstelijnspsycholoog zijn relatief vaak vrouw, iets hoger opgeleid dan de gemiddelde Nederlander, zelden van niet-Nederlandse herkomst en relatief vaak tussen de 25 en 44 jaar oud. Het gaat vooral om inter-persoonlijke problemen, depressie, angststoornissen en verwerkingsproblemen.

De kenmerken van de cliënten van de eerstelijnspsycholoog zijn over de afgelopen jaren vrijwel hetzelfde gebleven. Vanaf 1998 is het percentage cliënten van niet-Nederlandse afkomst iets toegenomen om zich daarna te stabiliseren. In het algemeen zijn de cliënten in de loop van de tijd iets hoger opgeleid geworden. In de aanmeldingsklachten van de cliënten bij de eerstelijnspsycholoog hebben zich in de loop van de tijd geen grote veranderingen voorgedaan.

Kinderen worden relatief weinig gezien door eerstelijnspsychologen. Toch heeft een eerstelijnspsycholoog het nodige te bieden voor kinderen en jeugdigen. ${ }^{14}$ Wanneer meer kinderen en jeugdigen met matig ernstige problemen in de eerstelijn behandeld kunnen worden, zouden de wachtlijsten in de jeugdzorg korter kunnen worden.

Daarnaast zou de eerstelijnspsycholoog zich ook meer kunnen gaan richten op de ouderen.

${ }^{15,16}$ Slechts 2-3\% van de cliënten bij de eerstelijnspsycholoog was ouder dan 65 jaar. Onderzoek heeft echter aangetoond dat bij beëindiging van de hulpverlening door een eerstelijnspsycholoog bij $69 \%$ van de ouderen positief effect wordt aangetroffen. ${ }^{16}$ 
Emmen, M.J., Meijer, S.A., Verhaak, P.F.M. Positie van de eerstelijnspsycholoog in de geestelijke gezondheidszorg. TSG: Tijdschrift voor Gezondheidswetenschappen: 2008, 86(3), 142-149

Ten slotte zou het waardevol zijn als de eerstelijnspsycholoog zijn hulp toegankelijker en beter toepasbaar zou kunnen maken voor cliënten met een andere culturele achtergrond, ${ }^{17} \mathrm{die}$ thans sterk ondervertegenwoordigd zijn in het cliëntenbestand van de eerstelijnspsycholoog.

\section{Is de hulpverlening gedurende de afgelopen tien jaar veranderd?}

Het grootste deel van de werkzaamheden van de eerstelijnspsycholoog bestaat uit het geven van behandeling. De wachttijden lijken eerder toe dan af te nemen. De gemiddelde duur van de behandeling is gedurende de afgelopen negen jaar afgenomen van vijftien sessies tot zeven sessies in 2006. Het vermoeden bestaat dat steeds stringentere verzekeringsvoorwaarden een rol hebben gespeeld bij deze afname van de behandelduur. Het past niet binnen de doelstellingen van de versterking van de eerstelijns GGZ dat de wachttijd voor cliënten niet korter wordt. De hulp van een eerstelijnspsycholoog dient immers laagdrempelig en direct bereikbaar te zijn. De inzet van andere hulpverleners dan alleen eerstelijnspsychologen voor het leveren van eerstelijnspsychologische zorg, biedt hier mogelijk uitkomst.

\section{Zijn de verwijsstromen de afgelopen tien jaar gewijzigd?}

Gedurende de afgelopen jaren is het percentage cliënten dat via de huisarts naar de eerstelijnspsycholoog verwezen wordt geleidelijk afgenomen en het percentage cliënten dat op eigen initiatief komt, geleidelijk toegenomen. De eerstelijnspsycholoog is in de loop van de tijd meer naar de tweedelijns GGZ gaan verwijzen.

De eerste bevinding past niet bij het streven naar een centrale positie van de huisarts als poortwachter, ondersteund door het AMW en de eerstelijnspsychologen. Het lijkt er wel op te wijzen dat de eerstelijnspsychologen steeds bekender worden bij de algemene bevolking. Zij worden immers ook gevonden zonder hulp van een doorverwijzer. Het ontbreken van een "poortwachter" in meer dan een kwart van de gevallen zou een verklaring kunnen zijn voor de toename van de verdere doorverwijzingen van de eerstelijnspsycholoog naar de tweedelijns GGZ.

Het vinden van een eerstelijnspsycholoog zal voor de cliënt nog makkelijker gaan worden wanneer in 2008 uitgebreide informatie over de zorgaanbieders van eerstelijnspsychologische zorg op de site www.kiesbeter.nl geplaatst zal worden.

\section{Methodologische kanttekeningen}

De gegevens waarop we deze antwoorden baseren zijn afkomstig van enquêtes (1998, 2002) die afgenomen zijn onder alle als eerstelijnspsycholoog geregistreerde psychologen, en van registraties van een vijftigtal psychologen die participeerden in LINEP (2004 - 2006).

De respons op de enquêtes was ongeveer $50 \%$. Respondenten en niet-respondenten verschilden niet van elkaar met betrekking tot geslacht, regionale spreiding en mate waarin men in regionaal overleg participeerde. De psychologen die voor LINEP registreren zijn zo geselecteerd dat ze wat betreft hun spreiding over Nederland respectievelijk over stad en platteland en wat betreft de praktijkgrootte (solo versus groepspraktijken) representatief zijn voor de eerstelijnspsychologen in Nederland. Op basis hiervan menen we dat de verzamelde gegevens over de periode 1998 - 2006 representatief zijn voor wat zich in die periode onder eerstelijnspsychologen afspeelde.

Een probleem is dat in de beide enquêtes soms antwoordcategorieën gebruikt worden die licht afwijken van die in LINEP. Dit maakte het lastig om de aanmeldingsklachten over de tijd goed te vergelijken. Er is dan ook voor gekozen deze wel voor alle jaren te presenteren, maar alleen voor de jaren 2004 tot en met 2006 te toetsen. Indien LINEP gecontinueerd wordt, zal het beter mogelijk zijn over de diverse gegevens duidelijke trends te bekijken.

\section{CONCLUSIE}

Geconcludeerd wordt dat de sterkere positie van de eerstelijnspsycholoog in de eerstelijn vooral zichtbaar is in de toename van het aantal eerstelijnspsychologen. De overheidsmaatregelen hebben niet veel veranderingen teweeg gebracht in de 
Emmen, M.J., Meijer, S.A., Verhaak, P.F.M. Positie van de eerstelijnspsycholoog in de geestelijke gezondheidszorg. TSG: Tijdschrift voor Gezondheidswetenschappen: 2008, 86(3), 142-149

cliëntenpopulatie, het type hulpverlening en de verwijzingenstroom naar en vanuit de eerstelijnspsycholoog. Mogelijk dat de opname van eerstelijnspsychologische zorg in de basisverzekering hier verandering in gaat brengen.

In de toekomst blijft voor de eerstelijnspsycholoog het samenwerken met andere disciplines belangrijk. Recent onderzoek toont aan dat huisartsen de samenwerking met de eerstelijnspsycholoog steeds beter beoordelen. ${ }^{18}$ De goede samenwerking tussen huisarts en eerstelijnspsycholoog blijkt ook uit de Landelijke Eerstelijns Samenwerkings Afspraak (LESA) die de LVE met huisartsen gemaakt heeft over de behandeling van depressie ${ }^{19}$ en angststoornissen. ${ }^{20}$

Ook zou de eerstelijnspsycholoog zich in de toekomst meer kunnen gaan profileren op het gebied van preventie. Van de cliënten van eerstelijnspsychologen lijdt $15 \%$ aan een depressie. Preventie van depressie is voor de komende jaren een beleidsspeerpunt van de landelijke overheid. ${ }^{21}$ Een van de actiepunten daarbij is om preventie van een depressieve stoornis bij mensen met depressiviteitklachten structureel vorm te geven binnen de eerstelijns gezondheidszorg. Deze vorm van preventie wordt vanaf 1 januari 2008 bekostigd via de zorgverzekeringswet. Dat geeft eerstelijnspsychologen de mogelijkheid om zich te profileren als één van de aanbieders van interventies gericht op preventie van depressie en andere psychische stoornissen. Het beleidsprogramma 2006-2010 van de LVE wijst ook op die mogelijkheid. ${ }^{22}$

POSITION OF THE PRIMARY CARE PSYCHOLOGIST IN THE MENTAL HEALTH CARE Primary care psychologists provide short term mental health services for psychological and psychosocial problems in primary care. The impact of different measures to strengthen the mental health services in the primary care on the capacity of primary care psychologists and provided care in the last ten years will be studied. The primary care psychologists' capacity has increased. The care provided by the primary care psychologist didn't change very much. The average time of treatment has been reduced. Also the pattern of referrals to and from the primary care psychologists did not change. The majority of the primary care psychologists' clients was referred by the general practitioner and the primary care psychologist referred one third of his clients to specialized somatic and mental health care. Only the increased capacity of primary care psychologists is an indication of the stronger position of the primary care psychologist in the primary health care. Possible consequences of the forthcoming inclusion of primary care psychology in the standard package of essential health care of Dutch health insurances will be discussed.

\section{LITERATUUR}

1. Wentink M, Hattum MJC, Hutschemaekers G. De eerstelijnspsycholoog gevolgd. Utrecht: Trimbosinstituut, 2002.

2. LVE. Richtlijn intake en indicatiestelling. Amsterdam: LVE, 2005.

3. Ministerie van Volksgezondheid, Welzijn en Sport. Beleidsvisie GGZ. Den Haag: Elkerhout, 1999.

4. NIP, LVE. Werk en psychische klachten. Richtlijn voor psychologen. Amsterdam: NIP/LVE, 2005.

5. Stichting HKZ. Certificatieschema Eerstelijnspsychologenpraktijken. PLAATS: Stichting HKZ, 2004.

6. NIP. Kwalificatieregeling Eerstelijnspsychologie. Amsterdam: NIP, 2005. 
Emmen, M.J., Meijer, S.A., Verhaak, P.F.M. Positie van de eerstelijnspsycholoog in de geestelijke gezondheidszorg. TSG: Tijdschrift voor Gezondheidswetenschappen: 2008, 86(3), 142-149

7. IJland CM, Drouven LE. Eindrapportage project Verruiming financiële toegankelijkheid eerstelijnspsychologen. Enschede: HHM, 2003.

8. Meijer SA, Zantinge EM, Verhaak PFM. Evaluatie versterking eerstelijns GGZ: Eindrapportage landelijk onderzoek. Utrecht: NIVEL, 2004.

Verweij A, Lucht F van der. Wat is de huidige situatie? In: Volksgezondheid Toekomst

9. Verkenning, Nationaal Kompas Volksgezondheid. Bilthoven: RIVM, <http://www.nationaalkompas.nl> Bevolking \Scholing en opleiding, 6 december 2006.

Landelijke commissie geestelijke volksgezondheid. Zorg van velen. Eindrapport van de

10. landelijke commissie geestelijke volksgezondheid. Den Haag: Landelijke Commissie Geestelijke Volksgezondheid, 2002.

11. Verhaak PFM, Emmen MJ, Winckers M. Het aanbod aan eerstelijns psychologische zorg. De Psycholoog 2007;42:XX-XX.

12. Verhaak PFM, Groenendijk J, Zantinge EM, Vonk E, Voordouw I, Veen C van de. GGZconsultaties aan de Eerstelijnszorg: eindrapportage. Utrecht: NIVEL, 2006.

13. Hingstman L, Kenens RJ. Cijfers uit de registratie van huisartsen - peiling 2007.

Utrecht: NIVEL, 2007.

Meer A van der, Salehi-Roos L. Kinderen en jeugdigen in de eerste lijn. In: Lamers E,

14. Bosch F, Hinderink L, Verschuren C (red). Handboek psychologie in de eerstelijn.. Amsterdam: Hartcourt Assessment, 2006, p.283-300.

Broek E. Ouderen en de eerstelijnspsychologie. In: Lamers E, Bosch F, Hinderink L,

15. Verschuren $C$ (red). Handboek psychologie in de eerstelijn. Amsterdam: Hartcourt Assessment BV, 2006, p.301-15.

16. Have M ten, Depla M, Pot AM. Welke rol speelt de eerstelijnspsycholoog voor ouderen met psychische problemen? Utrecht: Trimbos/LVE, 2007.

Boedjarath I, Colijn S. Culturele diversiteit in de eerstelijn. In: Lamers E, Bosch F,

17. Hinderink L, Verschuren $C$ (red.) Handboek psychologie in de eerstelijn. Amsterdam: Hartcourt Assessment, 2006, p.316-31.

Emmen MJ, Meijer SA, Heideman JMC, Laurant MG, Verhaak PFM. Versterking van de

18. eerstelijns GGZ: Effecten op langere termijn. Tijdschr Gezondheidswet 2007;85:16673.

19. Romeijnders ACM, Lamers ETT, Vriezen JA, et al. Landelijke Eerstelijns

19. Samenwerkings Afspraak Depressieve stoornis. Huisarts Wet 2006;49:209-12.

20. Vriezen JA, Lamers ETT,Faber E, et al. Landelijke Eerstelijns Samenwerkings Afspraak Angsstoornissen. Huisarts Wet 2007;50:S1-S4.

Meijer SA, Smit F, Schoemaker CG, Cuijpers P (red). Gezond verstand. Evidence-

21. based preventie van psychische stoornissen. RIVMrapport 270672001. Bilthoven / Utrecht: RIVM / Trimbos-instituut, 2006.

22. LVE. Profileren, positioneren en excellereren vanuit een nieuw perspectief. Beleidsprogramma 2006-2010. Amsterdam: LVE, 2005. 


\section{FIGUREN EN TABELEN}

Figuur 1 Aantal eerstelijnspsychologen per 100.000 inwoners

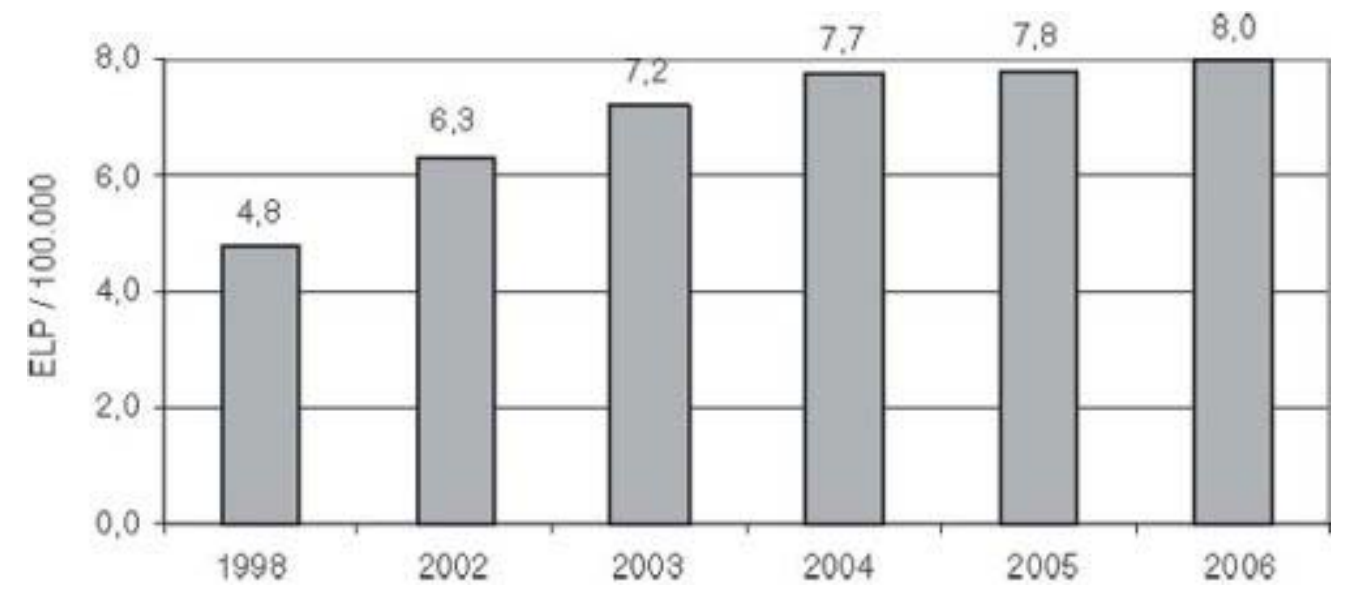

Tabel 1 Kenmerken van cliënten van de eerstelijnspsycholoog over de jaren 1998 tot en met 2006.

\begin{tabular}{|c|c|c|c|c|c|}
\hline \multicolumn{5}{|c|}{ Cliënten } & Nederlandse bevolking \\
\hline 1998 & 2002 & 2004 & 2005 & 2006 & 2006 \\
\hline 36 & 33 & 39 & 39 & 38 & 49 \\
\hline 65 & 67 & 61 & 61 & 62 & 51 \\
\hline
\end{tabular}

\section{Opleidingsniveau (\%)}

$\begin{array}{lllllll}\text { Geen opleiding / basisschool } & 4 & 4 & 8 & 8 & 8 & 10\end{array}$

LBO/Mavo

$\begin{array}{llllll}32 & 28 & 22 & 18 & 19 & 25\end{array}$

Havo / MBO / VWO

$\begin{array}{llllll}35 & 35 & 40 & 44 & 43 & 40\end{array}$

$\mathrm{HBO} / \mathrm{WO}$

$\begin{array}{llllll}30 & 32 & 30 & 31 & 31 & 25\end{array}$

\section{Herkomst (\%)}

Nederland

Anders

$\begin{array}{llllll}96 & 93 & 93 & 91 & 93 & 81 \\ 4 & 7 & 7 & 9 & 7 & 19\end{array}$

Gemiddelde leeftijd in jaren

$$
37,2 \quad 36,6 \quad 37,3 \quad 37,5 \quad 37,8 \quad 39
$$

Leeftijd in categorieën (\%)

$\begin{array}{lllllll}\text { 0-25 jaar } & 17 & 18 & 20 & 20 & 20 & 30 \\ 25-45 \text { jaar } & 59 & 58 & 53 & 52 & 51 & 29 \\ \text { 45-65 jaar } & 23 & 21 & 25 & 26 & 27 & 26 \\ 65 \text { jaar of ouder } & 2 & 3 & 2 & 2 & 3 & 14\end{array}$


Emmen, M.J., Meijer, S.A., Verhaak, P.F.M. Positie van de eerstelijnspsycholoog in de geestelijke gezondheidszorg. TSG: Tijdschrift voor Gezondheidswetenschappen: 2008, 86(3), 142-149

Bron: enquête onder eerstelijnspsychologen (1998, 2002) en LINEP (2004, 2005, 2006), CBS en RIVM kompas( Verweij A (RIVM), Lucht F van der (RIVM). Wat is de huidige situatie? In: Volksgezondheid Toekomst Verkenning, Nationaal Kompas Volksgezondheid. Bilthoven: RIVM, <http://www.nationaalkompas.nl> Bevolking $\$ Scholing en opleiding, 6 december 2006) 
Emmen, M.J., Meijer, S.A., Verhaak, P.F.M. Positie van de eerstelijnspsycholoog in de geestelijkg gezondheidszorg. TSG: Tijdschrift voor Gezondheidswetenschappen: 2008, 86(3), 142-149

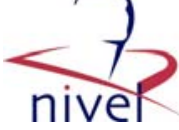

Tabel 2 Problemen voorkomend bij de cliënten van de eerstelijnspsycholoog, uitgedrukt in percentages

\begin{tabular}{|c|c|c|c|c|c|}
\hline \multicolumn{3}{|c|}{ \% cliënten } & \multicolumn{3}{|c|}{ \% cliënten } \\
\hline & 2002 & Probleemgebieden 2004, 2005 en 2006 & 2004 & 2005 & 2006 \\
\hline$=2.779$ & $\mathrm{n}=1.109$ & & $\mathrm{n}=3.512$ & $\mathrm{n}=4.179$ & $\mathrm{~N}=4.823$ \\
\hline
\end{tabular}

Probleemgebieden 1998 en 2002

\begin{tabular}{|c|c|c|c|c|c|c|}
\hline \multicolumn{7}{|l|}{ Psychisch } \\
\hline Trauma/rouw/scheiding & 8 & 9 & Aanpassings/verwerkingsproblemen & 16 & 18 & 18 \\
\hline Depressiviteitklachten & 14 & 11 & Depressies & 16 & 15 & 14 \\
\hline Fobie, vage angsten/paniekaanvallen & 8 & 7 & Angststoornissen & 13 & 13 & 14 \\
\hline Werk/studieproblemen, burnout/overspannen & 11 & 15 & Werk en studieproblemen & 11 & 9 & 8 \\
\hline Identiteitsproblemen/negatief zelfbeeld & 7 & 11 & Identiteitsproblemen & 5 & 6 & 5 \\
\hline Spanningsklachten & 13 & 6 & & & & \\
\hline Assertiviteitsproblemen & 7 & 6 & & & & \\
\hline Levens-/zingevingsproblemen & $\mathrm{nvt}^{*}$ & 3 & & & & \\
\hline Agressie/woede & nvt & 3 & & & & \\
\hline Dwangmatige klachten & 2 & 1 & & & & \\
\hline Identiteitsstoornis & nvt & 1 & & & & \\
\hline Totaal psychisch & 70 & 73 & & 60 & 61 & 59 \\
\hline \multicolumn{7}{|l|}{ Relationeel } \\
\hline Relatie problemen & 13 & 11 & Interpersoonlijke problemen & 23 & 23 & 24 \\
\hline Gezins en opvoedingsproblemen & 4 & 5 & Gezinsproblemen & 1 & 2 & 1 \\
\hline Totaal relationeel & 17 & 16 & & 24 & 25 & 25 \\
\hline \multicolumn{7}{|l|}{ Gezondheid } \\
\hline Psychosomatisch/somatoforme klachten & 5 & 3 & Psychosomatisch/somatoforme klachten & 5 & 4 & 5 \\
\hline Slaapproblemen & 3 & 2 & Klachten met betrekking tot slapen/eten/seks/ impulsbeheersing & 3 & 3 & 3 \\
\hline Seksuele problemen & 2 & 1 & & & & \\
\hline
\end{tabular}

This is a NIVEL certified Post Print, more info at http://www.nivel.eu 
Emmen, M.J., Meijer, S.A., Verhaak, P.F.M. Positie van de eerstelijnspsycholoog in de geestelijkg gezondheidszorg. TSG: Tijdschrift voor Gezondheidswetenschappen: 2008, 86(3), 142-149

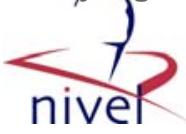

\begin{tabular}{|c|c|c|c|}
\hline Eetproblemen & 1 & 1 & \\
\hline Totaal gezondheid & 11 & 7 & \\
\hline \multicolumn{4}{|l|}{ Anders } \\
\hline Gedragsproblemen & nvt & 1 & Gedragsproblemen \\
\hline Psychose/decompensatie & nvt & 1 & Psychose/decompensatie \\
\hline \multirow[t]{4}{*}{ Verslaving } & nvt & 1 & Verslavingsproblemen \\
\hline & & & Leerproblemen \\
\hline & & & Zindelijkheidsproblemen \\
\hline & & & Tic-Stoornissen \\
\hline Anders & 2 & 3 & Anders \\
\hline $\begin{array}{l}\text { Totaal anders } \\
{ }^{*} \text { nvt }=\text { categorie ontbreek }\end{array}$ & 2 & 6 & \\
\hline
\end{tabular}

$\begin{array}{lll}8 & 7 & 8 \\ 3 & 2 & 3 \\ \text { nvt } & \text { Nvt } & \text { nvt } \\ \text { nvt } & 1 & 0 \\ 1 & 1 & 1 \\ \text { nvt } & 0 & 0 \\ \text { nvt } & 0 & 0 \\ 5 & 3 & 4 \\ 9 & 7 & 8\end{array}$

nvt = categorie ontbreek

This is a NIVEL certified Post Print, more info at http://www.nivel.eu 
Tabel 3 Percentage cliënten dat op eigen initiatief, op verwijzing van de huisarts of op verwijzing van een andere hulpverlener bij de eerstelijnspsycholoog terecht kwam

$\%$ cliënten van de eerstelijnspsycholoog

$\begin{array}{ccccc}1998 & 2002 & 2004 & 2005 & 2006 \\ \mathrm{n}=2769 & \mathrm{n}=1108 & \mathrm{n}=3527 & \mathrm{n}=4282 & \mathrm{n}=4854\end{array}$

Type verwijzer

Eigen initiatief

$\begin{array}{lllll}20 & 20 & 20 & 23 & 27\end{array}$

Huisarts

70

$68 \quad 71$

65

Andere hulpverlener*

10

12

9

12

*Andere hulpverleners zoals de bedrijfsarts of bedrijfsmaatschappelijk werker, het AMW, een andere eerstelijnspsycholoog of een schoolarts.

Bron: enquête eerstelijnspsychologen (1998 en 2002) en LINEP (2004, 2005 en 2006)

Tabel 4 Percentage doorverwijzingen vanuit de eerstelijnspsycholoog en type hulpverlener waarnaar verwezen is

\begin{tabular}{|c|c|c|c|c|c|}
\hline & $\begin{array}{c}1998 \\
\mathrm{n}=2477\end{array}$ & $\begin{array}{c}2002 \\
n=1085\end{array}$ & $\begin{array}{c}2004 \\
n=3513\end{array}$ & $\begin{array}{c}2005 \\
\mathrm{n}=4270\end{array}$ & $\begin{array}{c}2006 \\
\mathrm{n}=4811\end{array}$ \\
\hline \multicolumn{6}{|l|}{ Verwijsbestemming } \\
\hline $\begin{array}{l}\text { Geen doorverwijzing } \\
\text { /terugverwijzing }\end{array}$ & 93 & 89 & 88 & 89 & 89 \\
\hline Tweedelijns GGZ & 4 & 5 & 6 & 5 & 7 \\
\hline AMW & 0 & 1 & 1 & 0 & 0 \\
\hline Andere hulpverlener* & 3 & 5 & 5 & 5 & 4 \\
\hline
\end{tabular}

